\title{
Associated factors for celiac disease, and utility of tissue transglutaminase antibody tests for diagnosis: a matched case-control study
}

\section{Eman Jafar Al Alawi}

King Fahad university hospital, Imam Abdlrahman bin Faisal University, Dammam, Saudi Arabia Nagarajkumar Yenugadhati

King Saud bin Abdulaziz University for Health Sciences

Sundas Javad

King Saud bin Abdulaziz University for Health Sciences

\section{Hamdan Al Jahdli}

King Saud bin Abdulaziz University for Health Sciences

Motasim Badri ( $\nabla$ motasimb@hotmail.com )

King Saud bin Abdulaziz University for Health Sciences

\section{Research Article}

Keywords: Celiac disease, Genetics, Saudi, factors, screening, Tissue transglutaminase antibody tests

Posted Date: September 22nd, 2021

DOl: https://doi.org/10.21203/rs.3.rs-918587/v1

License: (9) This work is licensed under a Creative Commons Attribution 4.0 International License. Read Full License 


\section{Abstract}

\section{Background}

Prevalence of Celiac disease (CD) increased worldwide in recent decades. Approximately $53 \%$ of the 33.4 million Saudi population are genetically susceptible and 1.5\% develop CD. This underscores the importance of identification of factors associated with $C D$ and the diagnostic accuracy of $C D$ screening tests.

\section{Methods}

In this case-control study records of patients managed between January 2016 and July 2019 at Gastroenterology Department, King Abdul-Aziz Medical City, Riyadh, Saudi Arabia were reviewed. CD cases with confirmed intestinal biopsy were matched (1:1) by age with biopsy negative controls free of CD. Area under the curve (AUC) for anti-tissue transglutaminase $\lg A$ (TTG-IgA) and IgG (TTG-IgG) CD diagnostic tests were calculated and compared.

\section{Results}

The study included 270 cases and 270 controls. Sex distribution was similar in both groups. In a stepwise conditional logistic regression analysis, factors significantly associated with CD were family history (odds ratio $(\mathrm{OR})=7.76,95 \%$ confidence interval $(\mathrm{Cl}): 2.26-26.63, \mathrm{P}=0.001)$, Helicobacter pylori infection ( $\mathrm{OR}=1.72,95 \% \mathrm{Cl}: 1.10-2.71, \mathrm{P}=0.018$ ), diabetes mellitus ( $\mathrm{OR}=3.37,95 \% \mathrm{Cl}: 1.68-6.74, \mathrm{P}=0.001$ ), hypothyroidism ( $\mathrm{OR}=2.46,95 \% \mathrm{Cl}$ : $1.15-5.28, \mathrm{P}=0.02)$ and respiratory infections $(\mathrm{OR}=4.89,95 \% \mathrm{Cl} 2.26$ $10.56, P<0.001$ ). AUC for TTG-IgA test was 0.934 and for TTG-IgG was $0.787, P<0.001$. The optimal cutoff for TTG-IgA was >=12.7 U/ml, with $89 \%$ sensitivity and $86 \%$ specificity, and for TTG-lgG was >=3.5 $\mathrm{U} / \mathrm{ml}$, with $70 \%$ sensitivity and $77 \%$ specificity.

\section{Conclusion}

The findings of this study can inform strategies for CD screening and prevention. Public awareness campaigns for CD are urgently needed, particularly, for high-risk groups.

\section{Background:}

Celiac Disease (CD) is a complex digestive disorder caused by an abnormal immune reaction to gluten and usually results from interaction of genetic, immune, and environmental factors [1]. It is a chronic autoimmune disease known as gluten-sensitivity enteropathy where small intestinal mucosa is affected by chronic inflammation upon gluten intake [1,2]. It occurs in genetically susceptible individuals with Human Leukocyte Antigen (HLA) DQ2, DQ8 [1, 2]. CD can develop at any age and can lead to malnutrition and other serious health complications, including permanent intestinal damage $[1,3]$. 
CD diagnosis is often difficult to establish and usually is misdiagnosed as irritable bowel syndrome (IBS) due to long-term nonspecific symptoms [4,5]. As such, physicians should be aware of the possibility of celiac disease in such cases [4,5]. Screening strategies for CD are controversial and the need for mass population screening or testing only high-risk groups has been widely debated [6, 7]. In general, studies report higher prevalence of $C D$ based on serological testing compared to studies that report only confirmed cases through small intestinal biopsy $[6,8,9]$.

Diagnosis of $\mathrm{CD}$ patients is based on serological screening tests for antibodies that include tissue transglutaminase(TTG) or endomysial antibodies (EMA) followed by duodenal biopsy confirmation, which is considered the gold standard diagnostic tool $[2,6]$. Diagnosis of CD in early stage is important to initiate treatment and prevent development of serious morbid events such as gastrointestinal carcinoma or lymphoma $[10,11]$.

The prevalence of $C D$ has increased substantially in recent decades $[6,9]$. Recent projections indicate that the number of $C D$ cases for the Mediterranean region in 2020 would amount to 5 million with a medical cost of $€ 4$ billion over the 10 years period between 2010 and 2020 for management of symptomatic patients [12]. A meta-analysis conducted in Saudi Arabia in 2018 showed that seroprevalence of CD, based on serological testing was $2.7 \%$ and $1.4 \%$ for cases confirmed by biopsy [8]. A cross-sectional study estimated a prevalence rate of $1.5 \%$ among school children [6]. A study by Al-Hussaini et al. showed that more than half of the Saudi population is genetically susceptible to develop CD; despite $52.7 \%$ of the Saudi population carries CD genes, only $1.5 \%$ develop CD [13]. This underscores the role of environmental factors interacting with genetic susceptibility [13].

The etiology of CD remains not fully understood. The risk is higher in those with family history, particularly first-degree relatives, and is highest in twins $[7,14]$. However, many environmental factors can trigger CD in genetically susceptible individuals such as comorbidities, gastrointestinal infections (e.g. rotavirus), and antibiotics use [15-21]. Some comorbidities have been associated with higher risk of CD such as type 1 diabetes $[15,22]$. Gastrointestinal infections (e.g. Rotavirus), in particular, may initiate the onset of $C D$ through molecular mimicry resulting in autoimmunity and attacking of intestine [16, 23, 24]. Identification of these triggers may assist in early diagnosis as well as disease prevention through provision of prophylaxis and vaccination for high-risk group. However, most of the studies conducted in the Arab countries focused on prevalence and clinical pattern of disease. Although many studies evaluated the diagnostic utility of available CD serological tests, evidence for the optimal cut off for screening is lacking.

To our knowledge, there have been no published studies to identify factors associated with CD in Saudi Arabia. Therefore, the aim of this study is to determine factors associated with celiac disease and assess the diagnostic accuracy of the most widely used CD screening anti-tissue transglutaminase tests in Saudi Arabia.

\section{Methods}


This matched case-control study was conducted at King Abdulaziz Medical City (KAMC) in Riyadh, Saudi Arabia. The study was approved by the Institutional Review Board of King Abdullah International Medical Research Centre (IRB No. SP19/103/R).

Medical records of patients managed between January 1, 2016 and July 31, 2019 in the Gastroenterology Department at KAMC were reviewed. Celiac disease status was confirmed by serology and intestinal biopsy. Patients with inconsistent results in the pathology report and those who did not undergo endoscopy were excluded. Controls were recruited from the same department who underwent esophagogastroduodenoscopy (EGD) and had normal duodenum, and biopsy negative for CD. Matching was done on 1:1 basis, stratifying patients by age group (1-7, 8-15, 16-35, 36-50, >50 years). Inpatients and complicated cases such as cancer patients were excluded.

Preliminary data were provided by KAMC research data management center and patients were identified based on the ICD 10 disease coding system and cross checked by reviewing patient's electronic medical records (the hospital BESTCare database system). Variables collected included demographics, pathology reports, laboratory reports and comorbidities, such as age, body mass index (BMI), family history, diabetes, hypertension, heart disease, hypothyroidism, gastrointestinal infections (gastritis with Helicobacter pylori, gastroenteritis with enteric pathogens (Salmonella \& Shigella) and Rota virus. Furthermore, non-intestinal infections such as respiratory infections were included due to possibility of association with CD. Laboratory results data included anti-tissue transglutaminase IgA (TTG-IgA), antitissue transglutaminase IgG (TTG-IgG), anti-endomysial antibodies IgA (EMA), antigliadin antibodies $(A G G)$ and total serum $\lg A$.

\section{Statistical Analysis}

Numerical data variables were expressed as mean (SD) and categorical variables as frequencies. The $\chi^{2}$ or Fisher's exact tests were used, as appropriate, to compare categorical variables and the student-t test to compare numerical variables. A binary stepwise conditional logistic regression model was fitted to identify factors associated with CD. Celiac status was modeled as the dependent variable. Odds ratio (OR) and 95\% confidence intervals $(\mathrm{Cl})$ were used to express the strength of association. A receiver operating characteristics (ROC) curve was constructed to test and compare diagnostic accuracy of TTGIgA and TTG-IgG. Sensitivity and specificity based on selection of the best cut-off were reported. All tests were two-sided and a P value of $<0.05$ was considered statistically significant. IBM Statistical Package for Social Sciences SPSS version 25 (IBMSPSS, Chicago, USA) and STATA version 15 (StataCorp, Texas, USA) were used for data analysis.

\section{Results}

A total 540 patients were enrolled in this study; 270 cases and 270 controls. Demographic and clinical characteristics for cases and controls are summarized in Table 1. Distribution of gender in the two groups was similar, $P=0.409$. Approximately $58 \%$ of patients in each group were pediatric. However, there was a 
significant difference in mean (SD) BMI between the two groups; 21 (6) in cases vs 20 (7) in controls, $\mathrm{P}=$ 0.026 .

Table 1

Baseline characteristics

\begin{tabular}{|c|c|c|c|c|c|}
\hline \multirow{2}{*}{$\begin{array}{l}\text { Characteristics } \\
\text { Gender }\end{array}$} & \multicolumn{2}{|c|}{$\begin{array}{l}\text { Cases } \\
n \%\end{array}$} & \multicolumn{2}{|c|}{$\begin{array}{l}\text { Controls } \\
\mathrm{n} \%\end{array}$} & \multirow[t]{2}{*}{$\mathbf{P}$} \\
\hline & & & & & \\
\hline Male & 84 & 31.1 & 93 & 34.3 & \multirow[t]{2}{*}{0.409} \\
\hline Female & 186 & 68.9 & 177 & 65.6 & \\
\hline BMI (mean, SD) & 21 & 6 & 20 & 7 & 0.026 \\
\hline CD positive family history & 23 & 8.5 & 3 & 1.1 & $<0.001$ \\
\hline Diabetes & 54 & 20 & 17 & 6.3 & $<0.001$ \\
\hline Type 1 DM & 48 & 89 & 6 & 35 & \\
\hline Type 2 DM & 6 & 11 & 11 & 65 & \\
\hline Heart diseases & 9 & 3.3 & 11 & 4.1 & 0.649 \\
\hline Hypertension & 11 & 4.1 & 28 & 10.4 & 0.005 \\
\hline Hypothyroidism & 31 & 11.5 & 13 & 4.8 & 0.005 \\
\hline Iron deficiency anemia & 39 & 14.4 & 43 & 15.9 & 0.631 \\
\hline Growth hormone deficiency & 30 & 11.1 & 30 & 11.1 & 1.000 \\
\hline Vitamin D deficiency & 21 & 7.8 & 25 & 9.3 & 0.537 \\
\hline Down syndrome & 3 & 1.1 & 1 & 0.4 & 0.624 \\
\hline Asthma & 7 & 2.6 & 33 & 12.2 & $<0.001$ \\
\hline H. pylori gastritis & 76 & 28.1 & 51 & 18.9 & 0.011 \\
\hline Enteric infections & 2 & 0.7 & 4 & 1.5 & 0.686 \\
\hline Rota virus & 3 & 1.1 & 9 & 3.3 & 0.080 \\
\hline Respiratory infections & 49 & 18.1 & 12 & 4.4 & $<0.001$ \\
\hline
\end{tabular}

Family history was significantly higher among cases compared with controls $(8.5 \%$ vs. $1.1 \%, P=0.001)$ as well as diabetes ( $20 \%$ vs. $6.3 \%, \mathrm{P}=0.001)$; Type $1 \mathrm{DM}$ predominated in cases $(89 \%)$ while type $2 \mathrm{DM}$ was the predominant type among controls (65\%). The proportion of patients with hypothyroidism was 
significantly higher among cases (11.5\%) compared with controls $(4.8 \%), \mathrm{P}=0.005$. However, the proportion of patients with hypertension $(10.4 \%$ vs $4.1 \%, P=0.005)$ or asthma $(12.2 \%$ vs $2.6 \%, P=0.001)$ was significantly higher in controls compared with cases. No significant difference was observed in proportion of patients with heart diseases $(P=0.649)$, Iron deficiency anemia $(0.631)$ or down syndrome (0.624) between the two groups.

In regard to infectious diseases, the proportion of patients with Helicobacter pylori infection $(28.1 \% \mathrm{vs}$. $18.9 \%, P=0.011)$ or respiratory infections $(18.1 \%$ vs. $4.4 \%, P=0.001)$ was significantly higher in cases compared with controls. No significant difference was observed in the proportion of patients with enteric infection $(P=0.686)$ nor for Rotavirus $(0.08)$ between the two groups. $1.15-5.28$

In a stepwise binary conditional logistic regression, variables independently associated with the likelihood of $\mathrm{CD}$ were family history $(\mathrm{OR}=7.76,95 \% \mathrm{Cl} 2.26-26.63, \mathrm{P}=0.001)$, diabetes $(\mathrm{OR}=3.37,95 \% \mathrm{Cl} 1.68-$ $6.74, \mathrm{P}<0.001)$, hypothyroidism $(\mathrm{OR}=2.46,95 \% \mathrm{Cl} 1.15-5.28, \mathrm{P}=0.02)$, Helicobacter pylori infection (OR $=1.72,95 \% \mathrm{Cl} 1.10-2.71, \mathrm{P}=0.018)$, and respiratory infections $(\mathrm{OR}=4.89,95 \% \mathrm{Cl} 2.26-10.56, \mathrm{P}<0.001)$ (Table 2).

Table 2

Stepwise conditional logistic regression analysis for factors associated with celiac disease

\begin{tabular}{|llll|}
\hline Variables & Odds ratio & $95 \% \mathbf{C l}$ & $\mathbf{P}$ \\
\hline H. pylori & 1.72 & $1.10-2.71$ & 0.018 \\
\hline Family history & 7.76 & $2.26-26.63$ & 0.001 \\
\hline Diabetes & 3.37 & $1.68-6.74$ & $<0.001$ \\
\hline Hypothyroidism & 2.46 & $1.15-5.28$ & 0.021 \\
\hline Respiratory infections & 4.89 & $2.26-10.56$ & $<0.001$ \\
\hline
\end{tabular}

Of the several serological tests done, anti-tissue transglutaminase (TTG) test values differed significantly between cases and controls (Fig. 1). We therefore performed a further analysis to determine the accuracy for both forms of this test; the TTG-IgA test and the TTG-IgG test. Area under the curve (AUC) for the TTGIgA test was 0.9337 and for TTG-IgG test was 0.7868 ( Figs. <link rid="fig3">2</link>-A and 2-B). AUC of the two tests were significantly different $(P<0.001)$ as shown in Table 3 . The best cut off for each test was selected based on the value that provided maximum sensitivity and specificity. The best cut off for TTG-IgA was $>=12.7 \mathrm{U} / \mathrm{ml}$ with $89 \%$ sensitivity and $86 \%$ specificity. The best cut off for TTG-IgG was $>=$ $3.5 \mathrm{U} / \mathrm{ml}$ with $70 \%$ sensitivity and $77 \%$ specificity. These analyses shows the superiority of TTG-IgA for CD screening and diagnosis. 
Table 3

AUC comparison of TTG-IgA vs TTG-IgG screening tests for celiac disease

\begin{tabular}{|ll|}
\hline Test & ROC Area Std. Err. chi $^{2}$ df $\mathrm{Pr}>$ chi $^{2}$ Bonferroni $\mathrm{Pr}>\mathrm{chi}^{2}$ \\
\hline TTG-IgA (standard) & 0.9340 .012 \\
\hline TTG-IgG & $0.7870 .02247 .651<0.001<0.001$ \\
\hline
\end{tabular}

\section{Discussion:}

The present study identified independent factors associated with celiac disease in Saudi population, including family history, diabetes mellitus, hypothyroidism, respiratory infections, and $\mathrm{H}$. pylori infection. In addition, diagnostic accuracy of serological tests showed superiority of anti-tissue transglutaminase $\lg A$ as a screening tool for CD.

Our study findings concur with a previous population based study that reported a 2.5 times higher risk of CD among patients who had first degree relatives affected by CD in USA [14]. However, the higher magnitude of $C D$ risk observed among patients with familial link, in this study, indicate a population specific greater risk of CD in Saudi Arabia.

Furthermore, it is interesting to note the significant association between diabetes mellitus, hypothyroidism and CD in this study. Among diabetic CD cases, predominant number of patients had type 1 diabetes mellitus (T1DM). Similar findings were observed in previous studies, where prevalence of CD was $17.9 \%$ based on serology, and $11.3 \%$ based on biopsy among T1DM children in Saudi Arabia [25]. In addition, our results are consistent with previous studies that showed higher prevalence of hypothyroidism among celiac disease patients in Italy, Sweden, Brazil and other countries [26-30]. A 3fold higher prevalence of hypothyroidism was observed among CD cases ( $12.9 \%$ vs $4.2 \%$ in controls) in an Italian multicenter study [26], whereas the risk of hypothyroidism was over 4-fold in a Swedish study [27]. In a meta-analysis, a significant increase in the prevalence of hypothyroidism was found in CD patients compared to controls ( $\mathrm{OR}=3.38,95 \% \mathrm{Cl}: 2.73-4.20)$ [30]. In particular, $\mathrm{CD}$ was linked to autoimmune thyroid disease [29, 31-33]. Our findings support the link between autoimmune disorders and CD, possibly through a shared genetic predisposition in susceptible individuals [34]. It is noteworthy that genetic risk of CD was related to HLA genotypes DQ2 (90\%) and DQ8 that could account for the link to autoimmune disorders such as T1DM and autoimmune thyroid disease [34].

Although the present study found a positive association, the evidence for association between $\mathrm{H}$. pylori infection and CD has been controversial. Some studies reported H.pylori as a risk factor [35], some as a protective factor [36, 37], while others found no association [38]. Konturek et al., reported a higher frequency of $\mathrm{H}$. pylori in patients with $\mathrm{CD}$ than in controls (26\% vs. $20 \%$ ) in Germany [35]. However, other studies, including a recent meta-analysis found an inverse relationship between $\mathrm{H}$. pylori and CD; pooled OR was 0.56 indicating a protective effect $[36,37]$. Uyanikoglu et al., compared the prevalence of H.pylori in $C D$ positive and negative patients and found no significant difference [38]. But, small sample size of 
the cases $(n=31)$ would have limited the study power in detecting any significant difference. Although mechanistic evidence indicate a possible role of molecular mimicry in triggering autoimmune response in H. pylori infection, future research should address the ambiguity in evidence pertaining to development of $C D$ in genetically susceptible individuals [38-40].

In addition, the positive association observed between respiratory infections and CD, and lack of association with enteric infections caused by Shigella and Salmonella species indicate diverse role played by infectious agents in triggering autoimmune response. Our results were in agreement with an Italian cohort study, which reported a 2-fold higher risk of CD among high-risk newborns (with a family history) who experienced respiratory infections during their first 2 years of life [41]. Further studies are needed to confirm these findings, and relevant mechanistic pathway in high-risk groups.

The present study also assessed diagnostic accuracy of screening tests for CD, and superiority of TTG$\lg A$ as a screening tool is evident. This suggest that, in a resource-constrained setting, TTG- IgA could be the optimal CD screening tool. Based on our data, the best cut-off is $>=12.5 \mathrm{U} / \mathrm{ml}$ for this marker. However, our proposed cut-off was much lower than that was reported by Al-Hussaini et al., (anti-TTG-IgA of $>63 \mathrm{U} / \mathrm{ml}$ ) [25], likely due to differences in population under study; Al-Hussaini et al., study was based on high risk pediatric patients with type $1 \mathrm{DM}$, whereas the present study was based on both adults and children. It is interesting to note that the sensitivity (91.6\%) and specificity (93.6\%) of TTG-IgA was higher in high-risk population, indicating the need to identify broader high-risk groups based on associated factors [25].

To the best of our knowledge, this is the first case-control study to investigate the factors associated with $C D$ in Saudi Arabia. The strength of this study is selection of CD cases and controls without CD based on gold-standard intestinal biopsy. In contrast, many studies in the past used cases based on seropositivity and controls based on clinical absence of disease. Thus, it is difficult to exclude the potential of misclassification bias in those studies. In addition, we ensured absence of $C D$ among controls by selecting patients with normal duodenal biopsy, thereby avoiding inclusion of asymptomatic celiac patients as controls.

This study has some limitations that should be acknowledged. The associations of CD with comorbid conditions should be interpreted with caution, and further studies are needed to confirm the association of $C D$ with the comorbidities investigated in this study. This is a one-center hospital-based study, thereby limiting the generalizability of study findings. However, KAMC is a large referral tertiary medical city that caters to a wide range and spectrum of patients that may typically represent patients with $C D$ in Saudi Arabia. The known limitations of the retrospective design apply to this study. Prospective multicenter studies are needed to confirm our findings.

$C D$ remain largely under diagnosed [42-45]. Our study findings could aid in identifying high-risk groups for screening. Future studies in the Arab world should further explore CD associated risk factors in diverse populations, accuracy of available screening tests, and determining the role of environmental triggers, such as indoor and outdoor air pollution, life style and dietary habits associated on CD. 


\section{Conclusion}

In conclusion, this study identified several factors associated with CD that could aid in identifying highrisk groups. The superiority of TTG- IgA established in our setting could improve CD diagnosis and screening efforts, as mass screening is not feasible. In addition, development of relatively non-invasive accurate screening procedures may improve screening compliance, especially among children, where performing an endoscopy is challenging. Further prospective and multicenter studies are needed to expand the knowledge of risk factors and develop innovative screening tools for CD.

\section{Abbreviations}

AGG - antigliadin antibodies

AUC - area under the curve

$\mathrm{BMI}$ - body mass index

CD - Celiac disease

$\mathrm{Cl}$ - confidence interval

DM - diabetes mellitus

EMA - anti-endomysial antibodies (EMA)

HLA - human leukocyte antigen

H. pylori - Helicobacter pylori

IBS - irritable bowel syndrome

$\lg \mathrm{A}$ - immunoglobulin $\mathrm{A}$

KAMC - King Abdulaziz Medical City

$\mathrm{OR}$ - odds ratio

ROC - receiver operating characteristic

SD - standard deviation

T1DM - type 1 diabetes mellitus

TTG-IgA - anti-tissue transglutaminase immunoglobulin A

TTG-IgG - anti-tissue transglutaminase immunoglobulin G 


\section{Declarations}

\section{Ethics approval and consent to participate}

The study was approved by the Institutional Review Board of King Abdullah International Medical Research Centre (IRB No. SP19/103/R).

\section{Consent for publication}

Not applicable

\section{Availability of data and materials}

The datasets analyzed during the current study are not publicly available to maintain privacy and confidentiality of patient data.

\section{Competing interests}

The authors declare that they have no competing interests.

\section{Funding}

None

\section{Authors' contributions}

All authors contributed to study conceptualization and planning and reviewed the final version of the manuscript. EJA performed the statistical analysis and wrote the first draft of the manuscript. NY and MB contributed to statistical analysis and writing of the first draft of the manuscript. SJ, HAJ and AA contributed to data acquisition.

\section{Acknowledgements}


We are grateful for Mrs. Rawan Al Olyan, Mrs. Monirah A Albaijan and Marwa Al Abbas for their unwavering dedication and efforts in data acquisition.

\section{References}

1. Sollid LM. Coeliac disease: dissecting a complex inflammatory disorder. Nat Rev Immunol. 2002;2(9):647-55.

2. Husby S, Koletzko S, Korponay-Szabo I, Mearin M, Phillips A, Shamir R, et al. European Society for Pediatric Gastroenterology, Hepatology, and Nutrition guidelines for the diagnosis of coeliac disease. J Pediatr Gastroenterol Nutr. 2012;54(1):136-60.

3. Sarkhy AA, El Mouzan MI, Saeed E, Alanazi A, Alghamdi S, Anil S, et al. Clinical characteristics of celiac disease and dietary adherence to gluten-free diet among Saudi children. Pediatr Gastroenterol Hepatol Nutr. 2015;18(1):23-29.

4. Shahbazkhani B, Forootan M, Merat S, Akbari MR, Nasserimoghadam S, Vahedi $H$, et al. Coeliac disease presenting with symptoms of irritable bowel syndrome. Aliment Pharmacol Ther. 2003;18(2):231-5.

5. Fasano A, Berti I, Gerarduzzi T, Not T, Colletti RB, Drago S, et al. Prevalence of celiac disease in at-risk and not-at-risk groups in the United States: a large multicenter study. Arch Intern Med. 2003;163(3):286-92.

6. Al-Hussaini A, Troncone R, Khormi M, AlTuraiki M, Alkhamis W, Alrajhi M, et al. Mass screening for celiac disease among school-aged children: Toward exploring celiac iceberg in Saudi Arabia. J Pediatr Gastroenterol Nutr. 2017;65(6):646-51.

7. Rubio-Tapia A, Hill ID, Kelly CP, Calderwood AH, Murray JA. ACG clinical guidelines: diagnosis and management of celiac disease. Am J Gastroenterol. 2013;108(5):656-76.

8. Safı MA. Prevalence of Celiac disease in Saudi Arabia: meta-analysis. Global Vaccines and Immunology. 2018;3(1):1-6.

9. Safı M-AA. Celiac disease among at-risk individuals in Saudi Arabia. Saudi Med J. 2019;40(1):9-18.

10. Green PH, Fleischauer AT, Bhagat G, Goyal R, Jabri B, Neugut Al. Risk of malignancy in patients with celiac disease. Am J Med. 2003;115(3):191-5.

11. Marafini I, Monteleone G, Stolfi C. Association Between Celiac Disease and Cancer. Int J Mol Sci. 2020;21(11):4155.

12. Greco L, Timpone L, Abkari A, Abu-Zekry M, Attard T, Bouguerrà $F$, et al. Burden of celiac disease in the Mediterranean area. World J Gastroenterol. 2011;17(45):4971-78.

13. Al-Hussaini A, Alharthi H, Osman A, Eltayeb-Elsheikh N, Chentoufi A. Genetic susceptibility for celiac disease is highly prevalent in the Saudi population. Saudi J Gastroenterol. 2018;24(5):268-73.

14. Rubio-Tapia A, Van Dyke CT, Lahr BD, Zinsmeister AR, El-Youssef M, Moore SB, et al. Predictors of family risk for celiac disease: a population-based study. Clin Gastroenterol Hepatol. 2008;6(9):98387. 
15. Aktay AN, Lee PC, Kumar V, Parton E, Wyatt DT, Werlin SL. The prevalence and clinical characteristics of celiac disease in juvenile diabetes in Wisconsin. J Pediatr Gastroenterol Nutr. 2001;33(4):462-5.

16. Stene LC, Honeyman MC, Hoffenberg EJ, Haas JE, Sokol RJ, Emery L, et al. Rotavirus infection frequency and risk of celiac disease autoimmunity in early childhood: a longitudinal study. Am J Gastroenterol. 2006;101(10):2333-40.

17. Mårild K, Kahrs CR, Tapia G, Stene LC, Størdal K. Infections and risk of celiac disease in childhood: a prospective nationwide cohort study. Am J Gastroenterol. 2015;110(10):1475-84.

18. Kemppainen KM, Lynch KF, Liu E, Lönnrot M, Simell V, Briese T, et al. Factors That Increase Risk of Celiac Disease Autoimmunity After a Gastrointestinal Infection in Early Life. Clin Gastroenterol Hepatol. 2017;15(5):694-702.e5.

19. Canova C, Zabeo V, Pitter G, Romor P, Baldovin T, Zanotti R, et al. Association of maternal education, early infections, and antibiotic use with celiac disease: a population-based birth cohort study in northeastern Italy. Am J Epidemiol. 2014;180(1):76-85.

20. Pes GM, Bibbò S, Dore MP. Coeliac disease: beyond genetic susceptibility and gluten. A narrative review. Ann Med. 2019;51(1):1-16.

21. Caio G, Volta U, Sapone A, Leffler DA, De Giorgio R, Catassi C, et al. Celiac disease: a comprehensive current review. BMC Med. 2019;17(1):142.

22. Schwarzenberg SJ, Brunzell C. Type 1 Diabetes and Celiac Disease: Overview and Medical Nutrition Therapy. Diabetes Spectr. 2002;15(3):197-201.

23. Dolcino M, Zanoni G, Bason C, Tinazzi E, Boccola E, Valletta E, et al. A subset of anti-rotavirus antibodies directed against the viral protein VP7 predicts the onset of celiac disease and induces typical features of the disease in the intestinal epithelial cell line T84. Immunol Res. 2013;56(23):465-76.

24. Gómez-Rial J, Rivero-Calle I, Salas A, Martinón-Torres F. Rotavirus and autoimmunity. J Infect. 2020;81(2):183-89.

25. Al-Hussaini A, Sulaiman N, Al-Zahrani M, Alenizi A, El Haj I. High prevalence of celiac disease among Saudi children with type 1 diabetes: a prospective cross-sectional study. BMC Gastroenterol. 2012;12(1):180.

26. Sategna-Guidetti C, Volta U, Ciacci C, Usai P, Carlino A, De Franceschi L, et al. Prevalence of thyroid disorders in untreated adult celiac disease patients and effect of gluten withdrawal: an Italian multicenter study. Am J Gastroenterol. 2001;96(3):751-7.

27. Elfström P, Montgomery SM, Kämpe O, Ekbom A, Ludvigsson JF. Risk of Thyroid Disease in Individuals with Celiac Disease. J Clin Endocrinol Metab. 2008;93(10):3915-21.

28. da Silva Kotze LM, Nisihara RM, da Rosa Utiyama SR, Piovezan GC, Kotze LR. Thyroid disorders in Brazilian patients with celiac disease. J Clin Gastroenterol. 2006;40(1):33-36.

29. Ch'ng CL, Jones MK, Kingham JG. Celiac disease and autoimmune thyroid disease. Clin Med Res. 2007;5(3):184-92. 
30. Sun X, Lu L, Yang R, Li Y, Shan L, Wang Y. Increased Incidence of Thyroid Disease in Patients with Celiac Disease: A Systematic Review and Meta-Analysis. PLoS One. 2016;11(12):e0168708.

31. Farahid O, Khawaja N, Shennak M, Batieha A, El Khateeb M, Ajlouni K. Prevalence of coeliac disease among adult patients with autoimmune hypothyroidism in Jordan. East Mediterr Health Journal. 2014;20(1):51-5.

32. Cuoco L, Certo M, Jorizzo RA, De Vitis I, Tursi A, Papa A, et al. Prevalence and early diagnosis of coeliac disease in autoimmune thyroid disorders. Ital J Gastroenterol Hepatol. 1999;31(4):283-7.

33. Roy A, Laszkowska M, Sundström J, Lebwohl B, Green PH, Kämpe O, et al. Prevalence of Celiac Disease in Patients with Autoimmune Thyroid Disease: A Meta-Analysis. Thyroid. 2016;26(7):88090.

34. Barker JM, Liu E. Celiac disease: pathophysiology, clinical manifestations, and associated autoimmune conditions. Adv Pediatr. 2008;55(1):349-65.

35. Konturek P, Karczewska E, Dieterich W, Hahn E, Schuppan D. Increased prevalence of Helicobacter pylori infection in patients with celiac disease. Am J Gastroenterol. 2000;95(12):3682-83.

36. Narang M, Puri AS, Sachdeva S, Singh J, Kumar A, Saran RK. Celiac disease and Helicobacter pylori infection in children: Is there any Association? J Gastroenterol Hepatol. 2017;32(6):1178-82.

37. Amlashi Fl, Norouzi Z, Sohrabi A, Shirzad-Aski H, Norouzi A, Ashkbari A, et al. A systematic review and meta-analysis for association of Helicobacter pylori colonization and celiac disease. PLoS One. 2021;16(3):e0241156.

38. Uyanikoglu A, Dursun H, Yenice N. Is There any Association Between Celiac Disease and Helicobacter pylori? Euroasian J Hepatogastroenterol. 2016;6(2):103-05.

39. Cadamuro AC, Rossi AF, Maniezzo NM, Silva AE. Helicobacter pylori infection: host immune response, implications on gene expression and microRNAs. World J Gastroenterol. 2014;20(6):142437.

40. Smyk DS, Koutsoumpas AL, Mytilinaiou MG, Rigopoulou El, Sakkas LI, Bogdanos DP. Helicobacter pylori and autoimmune disease: cause or bystander. World J Gastroenterol. 2014;20(3):613-29.

41. Auricchio R, Cielo D, de Falco R, Galatola M, Bruno V, Malamisura B, et al. Respiratory infections and the risk of celiac disease. Pediatrics. 2017;140(4):e20164102.

42. Shah S, Leffler D. Celiac disease: an underappreciated issue in women's health. Womens Health (Lond). 2010;6(5):753-66.

43. Jinga M, Popp A, Balaban DV, Dima A, Jurcut C. Physicians' attitude and perception regarding celiac disease: A questionnaire-based study. Turk J Gastroenterol. 2018;29(4):419-26.

44. Menardo G, Brizzolara R, Bonassi S, Marchetti A, Dante GL, Pistone C, et al. Population screening for coeliac disease in a low prevalence area in Italy. Scand J Gastroenterol. 2006;41(12):1414-20.

45. Hin H, Bird G, Fisher P, Mahy N, Jewell D. Coeliac disease in primary care: case finding study. BMJ. 1999;318(7177):164-7. 
Figures

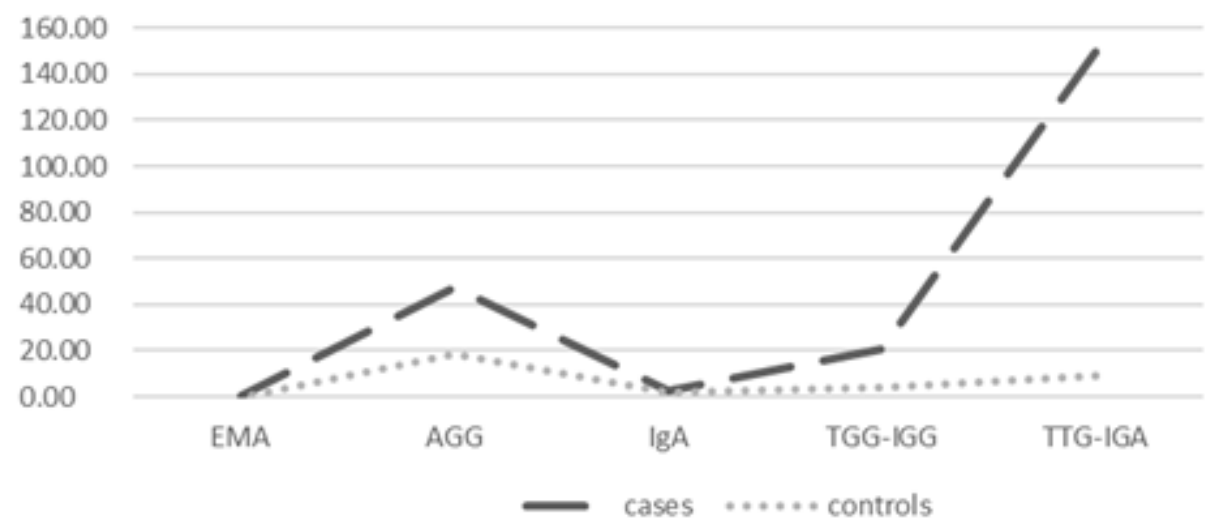

Figure 1

Celiac serology profile: cases vs controls

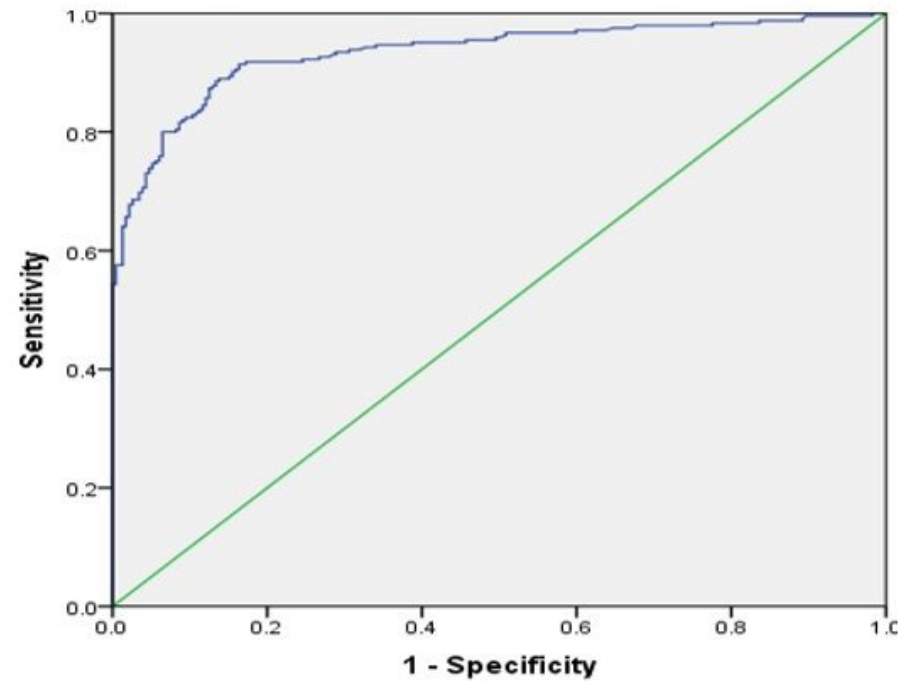

Figure 2-A. ROC curve for TTG-IgA

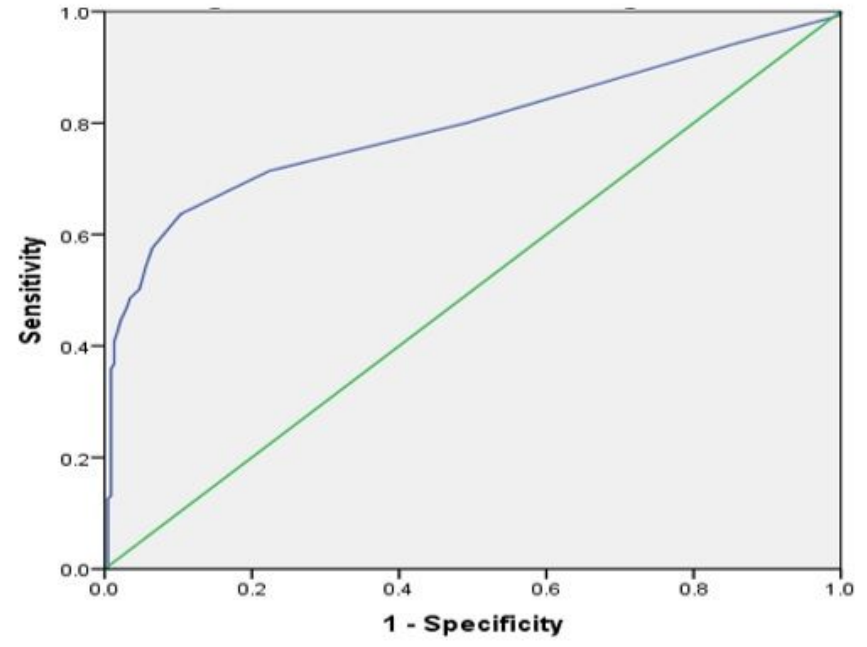

Figure 2-B. ROC curve for TTG-IgG

Figure 2

A. ROC curve for TTG-IgA. B. ROC curve for TTG-IgG 